\title{
A Plea For Affirming a Disjunct
}

BRIAN KIRBY

In the third year of our marriage, I discovered that my wife has disjunctive tendencies. I came at the same time to realize my own proclivity for the conditional. These revelations came about as I observed that, on those infrequent occasions when our young child dallied at bedtime, my wife's inclination was to say, 'Either you get to bed this instant or I will spank you." My own inclination in those cases was to say, 'If you don't get to bed this instant, I will spank you." With some adjustment to my logical intuitions, I have come to think of my wife's way of speaking as perfectly natural. We live, after all, in a pluralistic society.

What continues to be bothersome from a logical point of view, though, is that according to a least one popular text on critical reasoning, my wife has set the stage for our child to reason fallaciously, to commit the fallacy of affirming a disjunct. He is, we hope, going to aim at the result that he won't get spanked by making true the premise that he goes to bed:

\section{Either I go to bed this instant or I get spanked. \\ I go to bed this instant. \\ Therefore, I don't get spanked.}

The issue is exclusive or strong disjuction versus inclusive or weak disjunction. If my wife's utterance is taken as a strong disjunction, then
St. Lawrence University

my child commits no fallacy in his reasoning. If he goes to bed instantly and is thereupon spanked, he has other things being equal, a legitimate grievance. If my wife's utterance is taken as weak disjunction, it is hard to see how it could be effective since the odds for a spanking on promptly going to bed would be fifty-fifty. Of course it is strong disjunction, but how is that to be understood? Monroe Beardsley in Thinking Straight suggests the following:

\begin{abstract}
Whenever we find a disjunctive argument that commits the fallacy of affirming a disjunct, but somehow seems convincing, we should consider whether there are not some well-known facts from which we can draw a suitable new major premise. This doesn't make the original argument any less fallacious, but it transforms it into a valid onewhich might be what the arguer had in mind all the time.[1]
\end{abstract}

Beardsley's point in the context of my example is presumably that my wife really meant to say, "Either you will not get to bed this instant or I will not spank you." And my two-year old meant to reason from this major premise. This preserves weak disjuntion as the fundamental disjunctive concept and introduces strong disjunction as an essentially more complex and derivative notion. Irving Copi's discussion of disjunctive syllogisms 
in the classic, Introduction to Logic, involves much the same analysis. [2] But it just seems implausible.

In the example, at least part of the implausibility has to do with the context -threat of punishment-and part has to do with the requirement placed on the child to come up with unstated premises. As to the context, some writers are willing to grant that in cases such as my wife's utterance, the word "or" is being used in the strong sense and does not require supplementation by appeal to additional premises. [3] She meant what she said. And reasoning by affirming a disjunct is valid.

One reason for raising all this quibble is that as a result of teaching formal fallacies in an introductory critical reasoning course for a number of years, I am inclined to think that such fallacies tend to mislead and confuse students. It is easy for a teacher to use truth tables to demonstrate the fallaciousness of affirming a disjunct by putting a truth table for the argument on the chalk board, but I am not sure that this is at all illuminating for a student in a semester course in which propositional calculus may occupy at most a third of the class time. "Had we but world enough and time," we could point out that from the formal point of view, the choice of primitive logical operators is rather arbitrary. We could introduce weak disjunction, conjunction, and negation as primitive and then define strong disjunction as:

$$
p \approx q=d f(p \vee q) \&-(p \& q)
$$

and then we could go on to point out that, taking strong disjunction as primitive, weak disjunction has the following definition:

$$
p \vee q=d f(p \approx q) \approx(p \& q)
$$

We might finally point out that from the point of view of formal elegance, weak disjunction has an advantage over strong disjunction in that just it and negation can be used to define the rest of the logical operators in the propositional calculus. We would then be well on our way to a discussion of the stroke and dagger but far from the language of everyday argument and reasoning.

It is clear that the formal primitiveness of weak disjunction has relatively little bearing on the meaning of the word "or" in everyday reasoning. Sometimes it captures the meaning and sometimes it doesn't. The question is how "or" is being used on a particular occasion. One needs to examine cases. But at least one factor in the examination of cases is the state of mind or intention of the person uttering the disjunction or reasoning from it. Bertrand Russell [4] and Peter Strawson [5] associate "or" with the psychological state of hesitation, indecision, or incertainty. The hesitation is a hesitation about the facts or a hesitation over actions to pursuebroadly, contexts of choice about what to believe or what to do. Peter Geach, on the other hand, seems to be perverse, like me: "To many people, such recitation of the word 'or' suggests a feeling of dithering between alternatives; to me, on the other hand, it naturally suggests a threat-'-, or else -!' " [6] I would not venture to say that one suggestion is more natural than the other, but at least the "or" of threats is natural, and it is the "or" of strong disjunction.

A second reason for the brouhaha is that, the threatening "or" aside, some writers on logic and language seem to have missed some features of their own examples which seem to reveal recalcitrant cases of strong disjunction. In particular, when one examines the illustrations Russell offers for the use of "or" in hesitation and indecision, one finds that they present a mixed bag, in many cases clearly strong disjunction. The least complicated cases are those in which disjunction expresses ignorance of the truth values of the disjuncts. In one example in Human Knowledge: its Scope and Limits, a musteline fancier catches a glimpse of an animal and says, "That was a stoat or a weasel." [7] The assumption is that stoat and weasel are mutually exclusive classes. (Webster's Collegiate is not 
much help here. It says a stoat is a kind of weasel.) One might, Russell suggests, coin a word, "stosel," to mean "stoat or weasel," but then stose/ would be the class which was the logical sum of the two classes, stoat and weasel. The logical product of the two classes would be empty.

The concept, "stosel," would be a disjunctive concept of the strong sort, just as the concept, "child," is a strongly disjunctive concept including the two mutually exclusive concepts, "boy" and "girl;" and the concept, "metal," to use another of Russell's examples, may be a strongly disjunctive concept replaceable by "iron or copper or..., etc." [8] Russell does not refer to these concepts as strongly disjunctivemerely as disjunctive, but it is difficult if not impossible to understand them in any other way in their singular use. In their plural use, though, they might be weakly disjunctive. One can imagine someone, a priest at an ancient sacrificial rite, perhaps, giving the order, "Bring me some children," and being quite satisfied with a group consisting of both boys and girls. Russell does go on to make the further pragmatic point that whether or not concepts such as "metal" or "child" are disjunctive depends on one's interest in further discriminations, on one's interest, say, in conductivity or gender.

Disjunctive statements having to do with indecision about courses of action seem to break down into several distinct cases, some more complex than others. I take it that courses of action are means to goals. First, we may simply hesitate between incompatible goals. This seems to be the point of the following example from Russell:

I once, to test the story of Buridan's ass, put a cat exactly halfway between her two kittens, both too young to move: for a time she found the disjunction paralysing.[9]

This is clearly a case of strong disjunction.
Second, one may have a single goal, but suffer from ignorance as to which of two courses of action will lead to the goal. Desiring to go to Oxford,

You see a signpost saying 'To Oxford,' and presently you come to a fork in the road where there is no signpost. You then believe the proposition 'Oxford is along the right-hand road or Oxford is along the left-hand road. '[10]

From the example, one cannot tell exactly whether Russell includes the possibility that both roads lead to Oxford in one's disjunctive belief or not. The belief might be a case of weak disjunction. There is that case to consider. But then there is the case in which one knows that only one course of action will lead to one's goal, but one doesn't know which-as in the story of the lady and the tiger.

Finally there is the case, similar to the first, in which one knows that both courses of action will lead to the desired goal; the problem of ignorance has been solved. But one hesitates between two mutually exclusive courses of action. A helpful bystander at the fork tells you that both the righthand and left-hand roads lead to Oxford. He may even phrase the information disjunctively: "Well, you can take the right-hand road and get to Oxford or you can take the left-hand road. Either road leads to Oxford." Still the description of one's alternatives as one stands there like Russell's cat is a strong disjunction-"Either I go left or I go right." and I am inclined to think that the helpful bystander's first statement is also strong disjunction.

Whatever Russell's other concerns in Human Knowledge and Inquiry into Meaning and Truth, he does emphasize the point that the cognitive attitude of the utterer of an "or" statement needs to be taken into account. I hope to have injected some suspicion that in many paradigm cases of Russell's, the claim that the cognitive attitude of the utterer is that of hesitation or indecision does 
not support the notion that the logical operator must be that of weak disjunction.

More recently, in a seminal essay, "Logic and Conversation," H.P. Grice has maintained that the pragmatic norms of conversation, when applied to the standard rules of deduction, will help us sort out conversationally acceptable deductions from regressive deductive moves that violate the aims of conversation.[11] If I understand him correctly, the main drift of the essay is to show how, given certain maxims governing cooperative conversation, the context of the conversation, and the relevant background knowledge available to both parties, a listener can deduce the unstated conclusion or "conversational implicatum" of a speaker's remarks. Several of the maxims Crice offers are the maxims of Quantity-"Make your contribution as informative as is required (for the current purposes of the conversation)" - and the maxim of Quality-"Do not say what you believe to be false." [12]

In the hands of some writers, the maxim of Quantity as applied to "or" statements seems to lead directly to Russellian results. Developing Grice's idea, for example, Susan Haack writes, "... a speaker who asserts 'A or B' conversationally implies that he doesn't know whether it is A or B which is true." [14] That is, if you say 'A or $B^{\prime}$ when you know in fact that $A$ is true, you are violating the rule of Quantity, refraining from giving the amount of information appropriate to the conversation. Thus, if one says 'A or $B$ ' following the norms of cooperative conversation, one allows a listener to deduce correctly that one is in a state of hesitation or indecision as to the truth of $A$ and $B$.

Cooperative conversation, as Grice notes, tends toward some goal. In the case of argument understood as a species of cooperative conversation the goal is, ideally, joint recognition of some truth or agreement on the appropriateness of some course of action. Participants in a conversation may have different views about which statements are true or which actions best, but the process of argument is one through which they would anticipate resolving these differences. In general, I think, the aims of arguments in natural language are to arrive at true conclusions that are as strong as possible and positive rather than negative. To say that people want conclusions as strong as possible is basically to apply the first maxim of Quantity to argumentative conversation. A conclusion considerably weaker than the premises that support it is unsatisfactory. The glaring example in the propositional calculus is the rule of addition: from $p$, infer ' $p$ or $q$. ' Richard Jeffrew appeals to Grice's work in Formal Logic: Its Scope and Limits to draw just this moral. From the point of view of the normal aims of everyday argument, the conclusion of the inference moves us away from the information at hand. It is regressive and "pointless." [14] So, for the same Gricean reason, are the inferences:

$$
\text { p. }: p \vee-q ; p \cdot q \rightarrow p ; p^{*}-p \rightarrow q
$$

(Note that the disjunctive inferences here require weak disjunction for validity.)

People argue for the most part for positive claims rather than negative ones, about what a thing is rather than what it is not, about what to do rather than what not to do. There are, after all, an infinite number of uniformative statements saying what a thing is not. The lack of interest in what a thing is not may be part of the reason why affirming a disjunct is not a popular form of argument. However, one can image some fairly natural conversational exchanges in which it might be useful. Cases of rebuttal suggest themselves. For example, two musteline afficienados are walking in the woods.

A: Did you see the creature? It was either a stoat or a weasel.

$B$ : Yes, I believe it was a stoat.

A: (After a closer look) No, you are wrong. It is not a stoat. It is a weasel.

If we try to reconstruct this, it seems reasonable to say that $A^{\prime} s$ claim that 
it is a weasel is offered as a reason for the conclusion that it is not a stoat. And further, under the reconstruction, it is valid. I am not sure that it is valid because of any conversational implicature. Given just the disjunction, one may draw the 'implicatum' that $A$ does not know which species he has seen. One may also draw the implicatum that $A$ knows the animal was not an instance of both species, given the background that $A$ is versed in the conventions of taxonomy and the taxonomy of mustelines. But this is not necessary to say that we have found an unstated assumption to the effect that the animal is not both a stoat and a weasel. The implicatum follows from the original disjunction understood as strong disjunction. And the disjunction may be understood as strong disjunction partly as a result of the background context of taxonomic conventions.

What should we do about strong disjunction? If an "or" sentence is a case of strong disjunction, then the maneuver of affirming a disjunct is valid. But how do we know in evaluating a disjunctive argument which sense of "or" is being used? Jeffrey offers the advice that seems to be the conventional advice of logic texts: "In the absence of indications to the contrary, we assume that "or" statements are intended as disjunctions in our sense, i.e., the inclusive sense, in which the case where both components are true is included among the t(rue) cases for the disjunction." [15] But why should weak disjunction have this priority? Robert Fogelin, in Understanding Arguments: An Introduction to Informal Logic, says, "Since we can always define exclusive disjunction when we want it, there is no need to introduce it into our system of basic notions." [16] This rationale does occur in a chapter devoted to the formal aspects of the propositional calculus. Nevertheless, Fogelin, like Jeffrey, accepts the Gricean thesis, and so there remains a question about the appropriateness of the choice of weak disjunction. As
I noted earlier, we could perfectly well define weak disjunction in terms of strong disjunction when we wanted it. I can't escape thinking that the traditional choice is simply due to the formal training of the teacher in the propositional calculus. I think that when we are faced with an "or" sentence, we can, for the most part, be indifferent to the question. The elementary argument form which guides so much disjunctive reasoning, the disjunctive syllogism, is valid on either interpretation of "or". Some other cases need more care. The rule of addition is invalid for strong disjunction (but that rule with weak disjunction violates the maxim of quantity, anyway), and so is the rule of constructive dilemma (from " $(p \rightarrow q) \&(r \rightarrow s)^{\prime \prime}$ and " $p$ or $r$ ", infer "q or $s^{\prime \prime}$ ). Notoriously, affirming a disjunct is invalid for weak disjunction.

Faced with a case of reasoning involving the patterns, affirming a disjunct or constructive dilemma, then, one question to ask is whether the disjunct terms describe a domain in which one can have one's cake and eat it too, or not. A second question, equally important, is how the utterer of the disjunction conceives the domain. This second question takes us back to Russell's point about the cognitive state of the speaker, including the linguistic conventions according to which he sorts things out.

One needs indications that "or" is being used in one of the two senses for the few problematic cases, or one needs to know if there is a conversational implicatum to the effect that "not both $p$ and $q$ " is true. I don't see that this a serious problem. In many cases, the linguistic conventions that contribute to the implicatum tell all. The "logic" of color words, for example, requires that an object can't be both red and green at the same time. To say that the traffic light is red or green is to use mutually exclusive concepts and so to use strong disjunction. To say "You may have chicken or steak" is to 
employ the social conventions governing entrees and again to speak the language of strong disjunction. [17] Given the convention governing entrees, it follows deductively that you can't have both (or shouldn't, at the risk of violating social norms).

But this still seems a bit roundabout. What we are looking for in the conversational implicatum is a derived major premise, "not both $p$ and $q$," which will allow us to deduce "not $q$ " from p. But " $p \approx q$ " and $p$ immediately entail "not q." The issue is not so much that of conversational implicature in the case of affirming a disjunct as it is "contextual" or "conventional" implication. That is to say, a person knows or believes that two concepts or courses of action are mutually exclusive; it is a part of his way of using words and understanding the physical world. Or he may see that, in certain situations, the concepts overlap. In some cases, a thing or event may have both of two attributes or consequences. An object may be both red and round; an action may accomplish both of two seemingly incompatible goals. It may be that, in some tax brackets one may give to charity and also improve one's net income.

Or one may be faced with cases in which there may be joint causes for some event. In one of Monroe Beardsley's examples, an automobile is defective either because the battery is dead or because the starter is broken. [18] Given an understanding of the nature of mechanisms, one would tend to anticipate that several things could be wrong at the same time, and to conceive of the problem in terms of weak disjunction. But such a conception of the world may not be easy to adopt. In an early work on cognitive psychology, Jerome Bruner points out that the attainment of weak disjunctive concepts is as difficult as it is important. [19] His paradigm cases seem to be cases in which specialists have to recognize that either $x$ or $y$ or... or some combination could cause something, z. A typical specialist might be an allergist who believes that goldenrod or cat's dander or both are causing his patient's rash and sneezing. The allergist cannot infer as a result of a positive test for goldenrod that cat's dander is not also a culprit. "Allergy" is a weakly disjunctive concept as is "cases of automotive failure."

I draw the following results from this overlong discussion. First, many cases of affirming a disjunct are valid; and they are valid because they employ strong disjunction as the logical operator. Second, the priority given weak disjunction in many informal logic texts is misguided. Third, the moves such as Grice's conversational implicature, in as much as they may allow us to deduce a consequence such as "not both $p$ and q", are helpful in identifying cases of strong disjunction. But, finally, the linguistic presuppositions for the deduction are the way a speaker uses and understands words such as "child," "metal," "entree," "'allergy," and "road to Oxford." A person who thinks that a child may be both a boy and a girl does not yet understand the concept, "child." A person who thinks that an allergy cannot be caused by both goldenrod and cat's dander has not yet mastered the concept, "allergy".

\section{Notes}

[1] Monroe Beardsley, Thinking Straight, 4th edn. (Englewood Cliffs, NJ: Prentice-Hall, 1975), p. 46. See also, Beardsley's Writing with Reason, (Englewood Cliffs, NJ: Prentice-Hall, 1976), pp. 108-109, for another statement of the point.

[2] Irving Copi, Introduction to Logic, 6th edn. (New York: Macmillan, 1982) pp. 261-262. Copi also attempts to explain weak disjunction informally by appealing to the device, "and/or." But then, it seems that the "or" of "and/ or" is tacitly understood to be strong disjunction. Otherwise 
the explanation would be circular. See p. 282.

[3] See Norman Kretzmann, Elements of Formal Logic, (Indianapolis: Bobbs-Merill, 1985), pp. 28-29, Nicholas Rescher, Introduction to Logic, (New York: St. Martin's Press, 1964), p. 178, and Richard L. Purtill, Logic for Philosophers, (New York: Harper and Row, 1971), pp. 7-8, for examples.

[4] Bertrand Russell, An Inquiry into Meaning and Truth, (Baltimore: Penguin Books, 1962), p. 79, and Human Knowledge: Its Scope and Limits, (New York: Simon and Schuster, 1948), p. 126.

[5] Peter Strawson, Introduction to Logical Theory, (London: Methuen, 1952), p. 91.

[6] Peter Geach, Mental Acts, (New York: Humanities Press, 1957), p. 23.

[7] Op. Cit., pp. 125-126.

[8] An Inquiry into Meaning and Truth, p. 83.

[9] Ibid., p. 79.

[10] Ibid., p. 79.

[11] H. P. Grice, "Logic and conver- sation" included as an appendix to Robert J. Fogelin, Understanding Arguments, 2nd edn., (New York: Harcourt Brace Jovanovich, 1982), pp. 407-421.

[12] Ibid., p. 410.

[13] Susan Haack, Philosophy of Logics, (Cambridge: Cambridge University Press, 1978), p. 36.

[14] Richard Jeffrey, Formal Logic: Its Scope and Limits, 2nd edn. (New York: McGraw-Hill, 1981), p. 77.

[15] Ibid., p. 4.

[16] Op. cit., p. 166.

[17] Another of Fogelin's examples, p. 159.

[18] Beardsley, Thinking Straight, p. 45.

[19] Jerome Bruner, et al., A Study of Thinking, (New York: Science Editions, 1962), Chapter 6, "'On Disjunctive Concepts and their Attainment."

Professor Brian Kirby, Department of Philosophy, St. Lawrence University, Canton, Ny 13617 USA 